\title{
The role of the CS-US interval in bar press avoidance learning'
}

ROBERT C. BOLLES ${ }^{2}$, JOHN A. WARREN, JR. AND NORMAN OSTROV

Nine groups of rats were run in a single session with different CS-IIS intervals, ranging from $20 \%$ to $100 \%$ of the intertrial interval. The longer CS conditions led to markedly better acquisition of the bar press response.

A number of writers have noted that rats have considerable difficulty acquiring bar press avoidance behavior. Here, in the attempt to investigate this difficulty, we extend the systematic investigation of the parameters of shock (Chapman \& Bolles, 1964; Bolles \& Warren, 1965a, b) to the temporal parameters of the CS in bar press avoidance learning. Two experiments are reported in which the intertrial interval (ITI) remained essentially constant but the CS-US interval was different for different groups.

\section{Method}

Subjects. The Ss were 81 naive female SpragueDawley rats approximately $3 \mathrm{mo}$. old.

Apparatus. The operant conditioning box was a Foringer model $1102 \mathrm{M}$. The bar required about $1 \mathrm{~mm}$ of movement and force of $15 \mathrm{gm}$ to register a response; response feedback was provided by the sound of an empty Davis pellet dispenser with each response. Timing and programming apparatus were located in a separate room. The CS was a white noise of approximately $75 \mathrm{db}$ produced through the indigenous speaker in the Foringer box. The US was a constant current DC 1-ma shock delivered through a Lehigh Valley grid scrambler in Experiment 1 and through a GrasonStadler scrambler in Experiment 2.

Procedure. In Experiment 1, a bar press in the presence of the CS alone terminated it immediately and avoided the US, while a bar press in the presence of both CS and US terminated both immediately. The maximum possible duration of the US was 5 sec.; if it was terminated before 5 sec. the extra time on the US clock was added to the time out (TO) preceding the next CS. The time for TO plus CS was 25 sec. for all groups, but for different groups this interval was divided differently between TO and CS, with the CS portion of the interval for different groups being 5 , 12.5, 20 , or $25 \mathrm{sec}$. With the 25-sec. CS interval, if an avoidance response occurred at the beginning of a CS the CS would remain off for the duration of the $25-\mathrm{sec}$. interval at which point it would come on again preceding the next US by another $25 \mathrm{sec}$. Thus, once avoidance became well-established, it was possible for $S$ to get almost one trial ahead of the US. On the other hand, on trials on which the US came on and was turned off, the next CS onset was delayed for $5 \mathrm{sec}$. to be followed $25 \mathrm{sec}$. later by the next US. Ss were randomly assigned nine to a group and run in a single session 200 trials without any prior shaping of the response.

Experiment 2 was basically a replication of Experiment 1 . The principal methodological differences were the substitution of a Grason-Stadler shock scrambler and the elimination of the 5-sec. maximum shock or TO interval. Thus, for the 25-sec. CS group the whole ITI was occupied by the CS, so that it remained on continuously until an avoidance occurred, i.e., the CS only went off when an avoidance occurred. Again Ss were assigned nine to a group and were run in a single session of 200 trials. For different groups the CS-US interval was $5,12.5,20,22.5$, or 25 sec. Results

The reliability of group differences can be assessed in Figs. 1 and 2 which show the percentage of avoidances of individual Ss during the last 100 trials. There is evidently a large and significant improvement in avoidance behavior under the longer CS conditions. All groups with a CS of 20 sec. or longer are significantly superior to all groups with the more traditional short CS. Other response measures lead to the same conclusion, except in the case of the 25-sec. group in Experiment 2 where the percentage of avoidances is spuriously high. The Ss in this group tended, as do

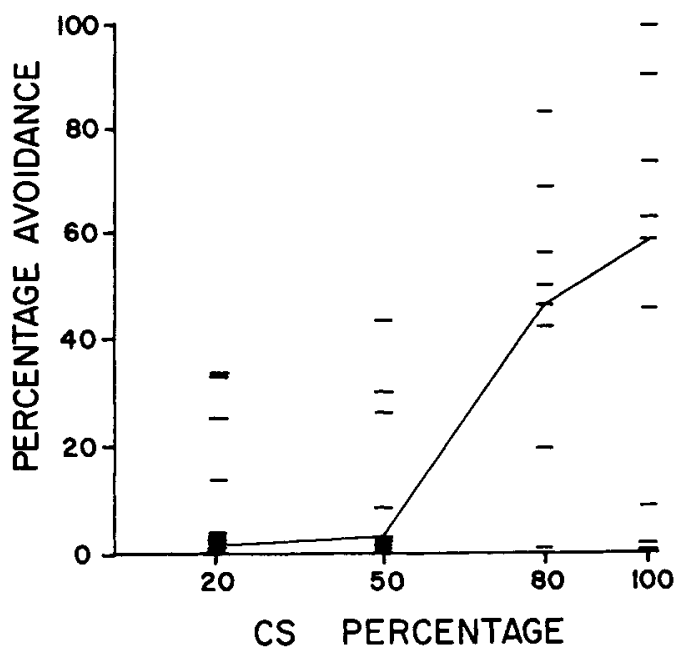

Fig. 1. Avoidance scores of individual Ss in Experiment 1 as a function of the percentages of the intertrial interval in which the $\mathrm{CS}$ is present and in which avoidance is possible. 


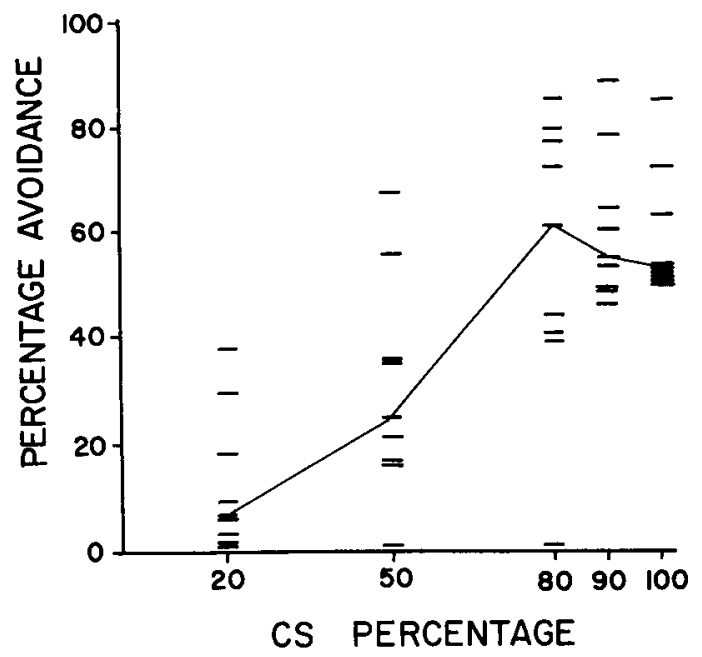

Fig. 2. Avoidance scores of individual Ss in Experiment 2.

all Ss, to respond in bursts when escaping shock. Since the conditions permitted avoiding the next shock by responding immediately after the last one, these shockescape bursts alternate with short latency avoidances. A few Ss continue for several hours thus "avoiding" on alternate trials. Acquisition curves for these Ss, accordingly, start near $50 \%$ and remain at that level. No other Ss showed such behavior.

\section{Discussion}

The most notable finding is the large superiority of Ss trained with the longer CS-US intervals. Other investigators (e.g., Behrend \& Bitterman, 1962; Low \& Low, 1962; Pearl \& Edwards, 1963) have suggested that better performance results primarily from the greater opportunity the longer CS-US interval provides for $S$ to make an avoidance response. Our results are entirely consistent with this interpretation, particularly our observation that a bar press is most probable during and immediately after shock and decreasingly probable as the time for the next trial approaches. The long CS makes it possible for the reinforcement contingencies, whatever they may be, to be applied to essentially all of S's operant response output, rather than just a small fraction of it. The only limiting factor on the length of the CS-US interval would seem to be that for optimum acquisition it should not cover so much of the ITI that $\mathrm{S}$ can make avoidance responses adventitiously by giving a burst of responses to shock. The Grason-Stadler shock scrambler appears to have some slight advantage over the Lehigh Valley Electronics scrambler in producing more avoidance behavior under the short CS conditions, probably because the shock it delivers produces a higher level of gross activity.

\section{References}

Behrend, E. R., \& Bitterman, M. E. Avoidance-conditioning in the goldfish: exploratory studies of the CS-US interval. Amer. $J$. Psychol., 1962, 75, 18-34.

Bolles, R. C., \& Warren, J. A., Jr. The acquisition of bar press avoidance as a function of shock intensity. Psychon. Sci., 1965a, 3, 297-298.

Bolles, R .C., \& Warren, J. A., Jr. Effects of delayed UCS termination on classical avoidance learning of the bar-press response. Psychol. Rep., 1965b, 17, 687-690.

Chapman, J. A., \& Bolles, R. C. Effect of UCS duration on classical avoidance learning of the bar-press response. Psychol. Rep., $1964,14,559-563$.

Low, L. A., \& Low, H.J. Effects of the CS-US interval length upon avoidance responding. J. comp. physiol. Psychol., 1962, $55,1059-1061$.

Pearl, J., \& Edwards, R. E. CS-US interval in the trace conditioning of an avoidance response. Psychol. Rep., 1963, 13, 43-45.

\section{Notes}

1. Supported by Research Grant GB-1650 from the National Science Foundation.

2. Now at University of Washington. 